\title{
Association Between Team Learning Behavior and Reduced Burnout Among Medicine Residents
}

\author{
Christopher G. Myers, PhD ${ }^{1,2}$, Heather F. Sateia, MD², and Sanjay V. Desai, MD ${ }^{1,2}$ \\ 'Carey Business School , Johns Hopkins University, Baltimore, MD, USA; ${ }^{2}$ School of Medicine, Johns Hopkins University, Baltimore, MD, USA.
}

KEY WORDS: burnout; medical education; organizational behavior.

J Gen Intern Med 33(12):2037-9

DOI: $10.1007 / \mathrm{s} 11606-018-4596-2$

(c) Society of General Internal Medicine 2018

\section{INTRODUCTION}

Burnout is a pervasive and alarming issue for physicians-intraining (residents), as well as practicing physicians, with significant consequences for resident well-being, care quality, and patient safety. ${ }^{1,]} 2$ Efforts to address burnout have emphasized both organization-level factors that create more supportive environments and individual-level factors that enhance physician resilience in the face of challenges. ${ }^{2,]} 3$ However, residents primarily work in teams - delivering patient care with fellow trainees, faculty, and interprofessional colleagues. Team practices and behaviors have been found to impact how individuals experience their work ${ }^{1,]}{ }^{4}$ - yet, the relationship of these team-level factors to resident burnout is still largely unknown.

Therefore, we explore the unique contribution of team practices in understanding resident burnout, focusing in particular on team learning behavior - a concept from organizational behavior research reflecting the extent to which team members gather information, reflect on experience, and share knowledge in their team. ${ }^{4}$ Engaging in this type of learning and reflection has been noted as an underlying feature of physician resilience ${ }^{3}$ and allows individuals to more adaptively approach work challenges. ${ }^{5}$ We thus examine the association between perceptions of team learning behavior and self-reported burnout, ${ }^{6}$ after accounting for the influence of relevant organizationand individual-level factors (specifically, perceptions of organizational support ${ }^{4}$ and individual learning and performance goal orientations ${ }^{5}$; see Table 1 note for descriptions) suggested by recent reviews of the burnout literature. ${ }^{2}$

\section{METHODS}

Our measures of interest were collected as part of a broader survey sent to all 148 members of the Johns

Published online July 26, 2018
Hopkins University School of Medicine Osler Medical Residency Training Program in internal medicine. This project received a quality improvement exemption from the Johns Hopkins University School of Medicine IRB.

Utilizing validated measures, we asked residents to assess the extent to which they perceived their assigned clinical team as engaging in learning behaviors (team learning behavior ${ }^{4}$ ), their perceptions of support from the residency program/department (supportive organizational context ${ }^{4}$ ), their level of burnout (emotional exhaustion ${ }^{6}$ ), and their individual goal orientations (learning, performance-prove, and performanceavoid $^{5}$ ) (see Table 1). Ninety-nine residents provided at least partial responses (response rate $=67 \%$ [99/148]), and 79 provided complete data on our study measures. Multivariable linear regression and conditional effect estimation were conducted using SPSS 24 (IBM); the significance threshold for 2 -sided $P$ values was set at 0.05 .

\section{RESULTS}

Residents reporting higher team learning behavior also reported significantly lower burnout $(B=-0.68, P=$ 0.03 ; Table 1, model 2), after accounting for their perceptions of organizational context and individual goal orientations (see Table 1, model 1 for results including only these specific organization- and individual-level factors). Moreover, results revealed a significant interaction between team learning behavior and individual learning goal orientation in predicting burnout $(B=$ $0.82, P=0.05$; Table 1, model 3). Conditional effects estimates revealed that the inverse association between team learning behavior and burnout was particularly evident for individuals with lower (1 standard deviation below mean; $B=-1.26,95 \%$ CI $[-2.09,-0.43], P=$ $0.004)$ or average $(B=-0.77,95 \% \mathrm{CI}[-1.37,-0.16]$, $P=0.01$ ) learning goal orientation. This association was not statistically significant for those with higher (1 
Table 1 Multivariable Regression Analysis of Burnout

\begin{tabular}{|c|c|c|c|c|c|c|}
\hline \multirow[t]{3}{*}{ Parameter } & \multicolumn{6}{|l|}{ Burnout $^{\dagger}$} \\
\hline & \multicolumn{2}{|l|}{ Model 1} & \multicolumn{2}{|l|}{ Model 2} & \multicolumn{2}{|l|}{ Model $3^{*}$} \\
\hline & $\begin{array}{l}B(\mathrm{SE}) \\
{[95 \% \mathrm{CI}]}\end{array}$ & $P$ & $\begin{array}{l}B(\mathrm{SE}) \\
{[95 \% \mathrm{CI}]}\end{array}$ & $P$ & $\begin{array}{l}B(\mathrm{SE}) \\
{[95 \% \mathrm{CI}]}\end{array}$ & $P$ \\
\hline Constant & $\begin{array}{l}7.27(1.68) \\
{[3.93,10.62]}\end{array}$ & $<0.001$ & $\begin{array}{l}8.28(1.70) \\
{[4.90,11.66]}\end{array}$ & $<0.001$ & $\begin{array}{l}5.12(1.23) \\
{[2.68,7.57]}\end{array}$ & $<0.001$ \\
\hline Supportive Organizational Context ${ }^{\S}$ & $\begin{array}{l}-0.87(0.25) \\
{[-1.38,-0.37]}\end{array}$ & 0.001 & $\begin{array}{l}-0.58(0.28) \\
{[-1.14,-0.03]}\end{array}$ & 0.04 & $\begin{array}{l}-0.67(0.28) \\
{[-1.22,-0.12]}\end{array}$ & 0.02 \\
\hline $\begin{array}{l}\text { Individual Goal Orientations" } \\
\text { LGO }\end{array}$ & $\begin{array}{l}-0.36(0.32) \\
{[-1.00,0.28]}\end{array}$ & 0.26 & $\begin{array}{l}-0.29(0.31) \\
{[-0.91,0.34]}\end{array}$ & 0.37 & $\begin{array}{l}0.00(0.34) \\
{[-0.68,0.68]}\end{array}$ & $>0.99$ \\
\hline PPGO & $\begin{array}{l}0.40(0.25) \\
{[-0.09,0.90]}\end{array}$ & 0.11 & $\begin{array}{l}0.40(0.24) \\
{[-0.08,0.89]}\end{array}$ & 0.10 & $\begin{array}{l}0.38(0.24) \\
{[-0.10,0.85]}\end{array}$ & 0.12 \\
\hline PAGO & $\begin{array}{l}0.12(0.20) \\
{[-0.27,0.51]}\end{array}$ & 0.55 & $\begin{array}{l}0.11(0.19) \\
{[-0.28,0.49]}\end{array}$ & 0.58 & $\begin{array}{l}0.14(0.19) \\
{[-0.23,0.52]}\end{array}$ & 0.45 \\
\hline Team Learning Behavior ${ }^{\mathrm{d}}$ & & & $\begin{array}{l}-0.68(0.31) \\
{[-1.30,-0.07]}\end{array}$ & 0.03 & $\begin{array}{l}-0.77(0.30) \\
{[-1.37,-0.16]}\end{array}$ & 0.01 \\
\hline Team Learning Behavior X LGO & & & & & $\begin{array}{l}0.82(0.41) \\
{[0.00,1.64]}\end{array}$ & 0.05 \\
\hline & Estimate & $P$ & Estimate & $P$ & Estimate & $P$ \\
\hline Model $R^{2}$ & 0.22 & 0.001 & 0.27 & $<0.001$ & 0.31 & $<0.001$ \\
\hline$\Delta R^{2}$ & & & 0.05 & 0.03 & 0.04 & 0.05 \\
\hline
\end{tabular}

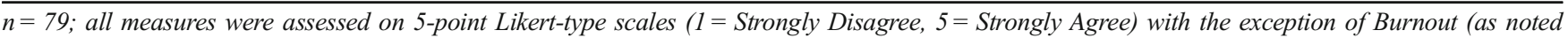
below); SE, standard error; 95\% CI, 95\% confidence intervals for unstandardized regression coefficients (B)

${ }^{\prime}$ Response to single emotional exhaustion item "I feel burned out from my work" on a 7-point frequency scale $(1=\text { Never, } 7=\text { Everyday })^{6} ; M=4.62$, $S D=1.63$

${ }^{7}$ Learning Goal Orientation (LGO) and Team Learning Behavior were mean centered for analysis in Model 3 to facilitate interpretation of coefficients ${ }^{\xi}$ Response to 5-item Supportive Organizational Context scale ${ }^{4}$ assessing the extent to which the respondent perceives his/her organization as providing adequate resources, information, and rewards for good performance; sample item: "We get all the information we need to do our work and plan our schedule"; $M=3.20, S D=0.67 ; \alpha=0.68$

"Response to 13-item scale 5 assessing the dimensions of Learning Goal Orientation (the propensity to approach tasks with a goal of learning) and performance goal orientation (both the desire to prove competence at work [Performance-prove Orientation] or avoid displaying incompetence [Performance-avoid Orientation]); Abbreviations: LGO, Learning Goal Orientation (5 items; sample item: "I enjoy challenging and difficult tasks at work where I'll learn new skills"; $M=4.06, S D=0.60 ; \alpha=0.87$ ); PPGO, Performance-Prove Goal Orientation (4 items; sample item: "I enjoy it when others at work are aware of how well I am doing"; $M=3.24, S D=0.73 ; \alpha=0.73) ; P A G O$, Performance-Avoid Goal Orientation (4 items; sample item: "I prefer to avoid situations at work where I might perform poorly"; $M=2.58, S D=0.98 ; \alpha=0.92$ )

"Response to 7-item Team Learning Behavior scale assessing the extent to which the respondent perceives his/her team as engaging in learning behavior; sample item: "This team frequently seeks new information that leads us to make important changes"; $M=3.26, S D=0.61 ; \alpha=0.73$

standard deviation above mean; $B=-0.27,95 \% \mathrm{CI}[-$ $1.00,0.46], P=0.46$ ) learning goal orientation (Fig. 1).

\section{DISCUSSION}

Results of this cross-sectional, exploratory survey of a single residency program revealed that residents' perceptions of greater learning behavior in their team were associated with significantly lower self-reported burnout. Indeed, the addition of team learning behavior (and its interaction with learning goal orientation) accounted for an additional 9\% of the variance in burnout among this sample (Table 1), above-andbeyond the variance explained by the types of organizationand individual-level factors emphasized in prior research on burnout. This association is of particular importance for resi- dency and medical education, as recent evidence indicates that younger physicians are at greater risk for burnout and that interventions for reducing burnout focusing on teamwork are rare. ${ }^{2}$ The significant interaction observed in the data further indicates that team learning behavior may be particularly beneficial for individuals with low to average levels of learning goal orientation, suggesting that team learning may be able to compensate for an individual's (lack of) learning orientation in reducing burnout.

Taken together, these findings suggest interventions to increase team learning behavior-for example implementing team-level mechanisms, habits, or practices for seeking feedback, sharing information, or openly discussing errors ${ }^{4}$ - should be explored more rigorously as a path forward in understanding the drivers of physician burnout. 


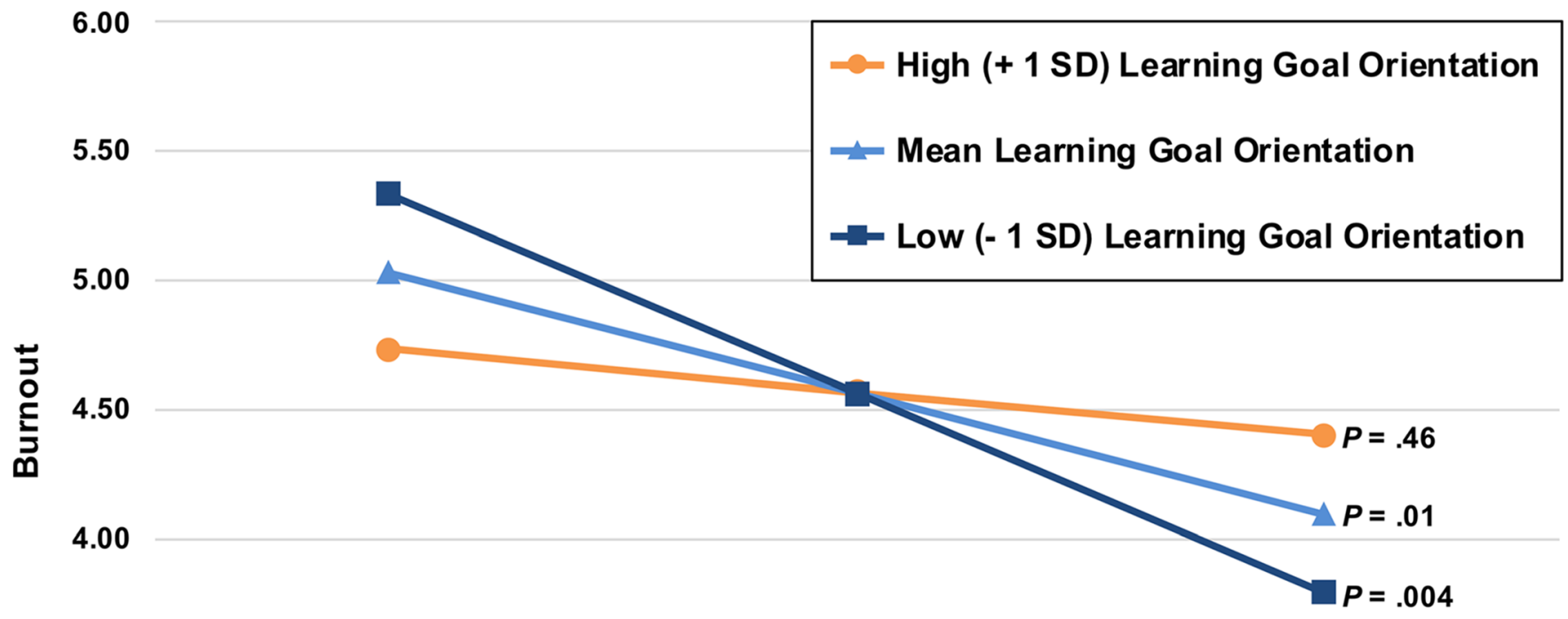

3.50

3.00 Low (- 1 SD)

Mean

High (+ 1 SD)

\section{Team Learning Behavior}

Fig. 1 Conditional effect estimates of team learning behavior on burnout at low (1 standard deviation below mean), average (mean), and high (1 standard deviation above mean) levels of individual learning goal orientation. Estimates of Burnout are based on setting all other model variables to their sample means, and correspond to a 7 -point frequency scale where $3=$ "Once a month or less", $4=$ "A few times a month", 5 = "Once a week", and $6=$ "A few times a week".6

Corresponding Author: Christopher G. Myers, PhD; Carey Business School Johns Hopkins University, Baltimore, MD, USA (e-mail: cmyers@jhu.edu).

\section{Compliance with Ethical Standards:}

Conflict of Interest: Dr. Sateia serves as a Welch Allyn Primary Care Advisory Board member. All other authors declare that they have no conflict of interest.

\section{REFERENCES}

1. Dyrbye L, Shanafelt T. A narrative review on burnout experienced by medical students and residents. Med Educ. 2016;50(1):132-149.
2. Panagioti M, Panagopoulou E, Bower $\mathbf{P}$ et al. Controlled interventions to reduce burnout in physicians: A systematic review and meta-analysis. JAMA Intern Med. 2017;177(2):195-205.

3. Zwack J, Schweitzer J. If every fifth physician is affected by burnout, what about the other four? Resilience strategies of experienced physicians. Acad Med. 2013;88(3):382-389.

4. Edmondson AC. Psychological safety and learning behavior in work teams. Admin Sci Quart. 1999;44(2):350-383.

5. VandeWalle DM. Development and validation of a work domain goal orientation instrument. Educ Psychol Meas. 1997;57:995-1015.

6. West CP, Dyrbye LN, Sloan JA, Shanafelt TD. Single item measures of emotional exhaustion and depersonalization are useful for assessing burnout in medical professionals. J Gen Intern Med. 2009;24(12):13181321. 